\title{
PIAAC Numeracy Skills and Home Use Among Adult English Learners
}

Margaret Becker Patterson, Research Allies for Lifelong Learning

\begin{abstract}
Research on adult English learners (ELs) typically (and appropriately) focuses on language-related skills. However, adult ELs may need numeracy instruction to navigate daily life or understand health information. Little is known about how ELs use numeracy skills at home and connections of skill use with related electronic numeracy skills. The purpose of this paper is to examine numeracy skill levels and home skill use of adult ELs. Employing Programme for the International Assessment of Adult Competencies (PIAAC) 2012/2014 data, the paper begins with identifying adult ELs' numeracy skill levels. The relationship of skill level with skill use is then analyzed to determine how six discrete groups of ELs at various skill levels employ numeracy skills, and to describe characteristics and backgrounds of each group for adult education instructors and interested stakeholders. The paper concludes with recommended implications for instruction from Curry's (2017) instructional guide based on the PIAAC Numeracy Framework.

Author Note: The author offers special thanks to Roofia Galeshi, Steve Reder, and three anonymous reviewers for helpful comments on earlier drafts of this paper.
\end{abstract}

Adult English learners (ELs) generally, and appropriately, wish to learn language-related skills. ELs, defined for this paper as immigrant adults with low English language skills in speaking, listening, reading, and/or writing, may seek to learn English to enhance their ability to communicate with, among others, neighbors, coworkers, child caretakers, and doctors in English. Additionally, adult ELs may want numeracy skills - practices in everyday life involving mathematics activities (Hogan et al., 2016) - to successfully navigate daily life, perhaps because they may have studied little or no numeracy initially in their home country or because many years have gone by and skills are forgotten or outdated. Many are adults over 24 years who do not fit a traditional full-time, immediate post-high-school model of learning in the United States. They may wish to help their children with schoolwork, determine shopping costs, or learn other numeracy skills for a sense of accomplishment (Coben \& Alkema, 2017; Ginsburg, 2017). As they age, adult ELs may also seek health information; numeracy skills are related to health-related outcomes and behaviors as well as health status (Organisation for Economic Co-operation and Development 
[OECD], 2013; Yamashita, Bardo, \& Liu, 2018; Yamashita \& Kunkel, 2015).

Also, little is known about how adult ELs use numeracy skills in their home lives and how skill use connects with electronic numeracy skills, specifically using spreadsheets and conducting online financial transactions. This paper's purpose is to examine numeracy skills and skill use at home of adults ages 25 to 74 years, who are first-generation immigrants and experiencing challenges with English proficiency, to better understand the needs of potential ELs. As the United States "has increasingly become a quantitative, information and technologically heavy society" (Cummins, Yamashita, \& Arbogast, 2018, p. 21) with the widest variability in numeracy skills of 24 OECD countries (Green, Green, \& Pensiero, 2015) and nearly 3 in 10 scoring at or below level 1 in numeracy (Grotlüschen, Mallows, Reder, \& Sabatini, 2016), investigating where numeracy skills of adult ELs place within that spectrum is important. A 2012/2014 Programme for the International Assessment of Adult Competencies (PIAAC) dataset permits largescale secondary analyses of numeracy skills and at-home numeracy use.

Beyond investigating numeracy needs of potential ELs and filling in knowledge gaps on their numeracy skills and skill use, this paper offers implications for practice. Since U.S. adult education programs are not universally designed with EL numeracy instruction in mind, ideas on program design and assessment may potentially increase numeracy skill levels and use along with language learning. Also relevant are instructional approaches to support strengthening EL numeracy skills.

\section{Literature Review}

\section{Numeracy vs. Mathematics}

To begin with, clearly distinguishing numeracy from mathematics is useful. PIAAC defines numeracy as "ability to access, use, interpret, and communicate mathematical information and ideas, in order to engage in and manage the mathematical demands of a range of situations in adult life" (PIAAC Numeracy Expert Group, 2009, p. 6; Rampey et al., 2016, p. 2). Ginsburg (2017) adds that numeracy skills and practices are more situated and less decontextualized and abstract than mathematics; instead they engage "with life's diverse contexts and situations" (p. 5758). Numeracy skills are considered essential, as their absence can have negative psychological and social impacts, and numeracy skills in personal or community contexts tend to be more focused on meaning than numeracy skills in other contexts, such as the workplace (Saal, Gholson, Machtmes, \& Machtmes, 2018).

\section{Numeracy Skills of Immigrants and English Learners}

Non-formal education may particularly benefit numeracy skills of immigrants (Krupar, Horvatek, \& Byun, 2017). Having skills to process and communicate mathematical information is foundational to immigrants' full participation in society, argue Batalova and Fix (2015). Perry (2017) adds that numeracy "serves as indicator for the extent to which immigrants have achieved important prerequisites for social participation in the host country" (p. 19).

Many, though not all, immigrants are also potential ELs. How mathematics vocabulary, context, and symbols are employed in instruction are key issues that can challenge ELs as they gain numeracy skills in English (Ni Riordain, Coben, \& Miller-Reilly, 2015; Stacey, 2016). ELs use multiple resources from experience (both in and outside the learning context) to gain numeracy. The 
intricate relationship between gaining numeracy skills and language is further complicated when language of instruction changes (Ni Riordain et al., 2015). ELs frequently come from countries and cultures in which instruction and assessments, mathematical symbols and language, and even value placed on numeracy skills differ from those in the United States, and instructional staff may easily make inaccurate assumptions about what ELs recognize, understand, and can do (Sellers \& Byrne, 2015; Stacey, 2016).

\section{PIAAC Numeracy Studies of Immigrants and English Learners}

How have PIAAC data been employed to date to contribute information on numeracy skills and at-home use among adult ELs? Multiple PIAAC studies have focused on immigrants to the United States, others on adults with low English proficiency. Neither immigrants nor ELs are homogeneous groups (Lind \& Mellander, 2016; OECD, 2018); while ELs are primarily (though not exclusively) immigrants, firstgeneration immigrants to the United States may have variable levels of English proficiency, from none to native fluency. Low assessed numeracy skills may partly reflect a language penalty from being assessed in a non-native language (i.e., English in the United States) rather than actual numeracy skills (Green et al., 2015; OECD, 2018). Therefore, distinguishing immigration status from language proficiency needs to occur thoughtfully (Lind \& Mellander, 2016). For this paper, adults selected were ages 25 to 74 years, first-generation immigrants, and experiencing challenges with English proficiency.

Initial PIAAC research indicates that immigrant adults tend to struggle with both literacy and numeracy compared with native-born adults (Batalova \& Fix, 2015, 2016; Krupar et al., 2017;
Massing \& Schneider, 2017; OECD, 2018). One in six U.S. adults are first-generation immigrants, compared with approximately 1 in 4 in Canada and 1 in 3 in Australia (Perry, 2017). Nearly a fourth (24\%) of first-generation immigrants ages 25 to 34 in the United States have less than a high school education (Batalova \& Fix, 2016).

Adults born outside the United States are overrepresented among adults with low numeracy skills (Grotlüschen et al., 2016). Half of immigrants (48\%) in Batalova and Fix' (2015) PIAAC study have numeracy skills at level 1 (or below). Adults who self-report speaking, understanding, reading, or writing English "not well" or "not at all" have numeracy scores averaging below level 1. Even immigrants ages 25 to 65 with a college education outside the United States have average numeracy scores at level 2, significantly lower than their U.S.educated immigrant peers (Batalova \& Fix, 2015). To interpret what these levels mean, OECD sets a proficiency threshold starting at level 3; in contrast, level 1 numeracy tasks require simple one-step or two-step processes involving, for example, performing basic arithmetic operations, understanding simple percentages, or identifying and using elements of simple graphs (OECD, 2013; Rampey et al., 2016).

\section{Adult Learners and Numeracy}

Gaining essential numeracy skills in adulthood implies further learning. Reder (2009b, 2013) distinguishes two sources of learners: adult immigrants and, less frequently, older adults and notes "increasing need for programs that focus on skill retention among older adults" (Reder, 2013, p. 21). Life-wide learning indicates gaining numeracy skills that can be applied at home or in educational or community settings (Massing \& Schneider, 2017; Reder, 2013). Examples of 
numeracy tasks at home include daily activities like balancing a checkbook, calculating interest, or measuring for recipes (Smith, 2009).

\section{Age, Education Attainment, and Family Background in PIAAC Findings}

PIAAC findings point to other factors of importance in analyses of numeracy skills among adult ELs: age, education attainment, and family background. Rates of aging in OECD countries, including United States, are steadily increasing as fertility rates decline and life expectancy increases (Paccagnella, 2016). Scandurra and Calero (2017) make the important point that younger cohorts of adults tend to have lengthier exposure to education than older cohorts; therefore, older adults may have lower skills in part due to less access to education.

Additionally, adult ELs may be disadvantaged because of less time in the host country, social environment, and family background as well as language differences (Massing \& Schneider, 2017; Scandurra \& Calero, 2017). In a causal path model of 30 OECD countries, Jonas (2018) reports high coefficients for years of education contributing to numeracy proficiency (0.48); greater education attainment does not entirely explain skill differences, however (Jonas, 2018; Massing \& Schneider, 2017; OECD, 2018; Reder, 2009a). In Scandurra and Calero's (2017) path modelling of PIAAC data, family background makes the strongest contribution to education (0.78).

\section{Practice Engagement: Numeracy Skills and At- home Use}

Multiple researchers discuss the relationship of skill acquisition (or loss) with skill use (Jonas, 2018; Scandurra \& Calero, 2017; Stoerent, Lundtrae, \& Boring, 2018). Two path models note factors contributing to at-home numeracy use:
Jonas (2018) reports that numeracy proficiency tends to benefit numeracy practices $(0.28)$ and Scandurra and Calero (2017) report education attainment contributes moderately to skill use at home (0.56). Stoeren et al. (2018) claim, “The 'use-it or lose-it'-hypothesis" assumes adult skills will diminish if not used (p. 579). A reciprocal relationship also exists between education attainment and skills, such that "education increases one's skills, and skilled persons normally have more education" (Stoeren et al., 2018, p. 593). Skill use may contribute to maintaining or promoting basic skills or even reduce skill loss with increasing age (Stoeren et al., 2018).

In the United States, high use of numeracy skills co-exists with low numeracy skills. Internationally, 1 in 5 adults with numeracy skill levels at level 1 or below reports never using numeracy skills at home; U.S. adult use of numeracy skills at home is generally high and tends to increase as skill levels rise (Grotlüschen et al., 2016). U.S. numeracy skill use is estimated at the $65^{\text {th }}$ percentile, second only to Finland, yet score means in assessed numeracy skills are below average (Jonas, 2018). With increasing age, at-home numeracy skill use tends to decline (Grotlüschen et al., 2016).

Recent PIAAC studies (Cummins et al., 2018; Saal et al., 2018; Scandurra \& Calero, 2017) apply practice engagement theory, which holds that adults' practices, or engagement in numeracy or literacy events in daily life, impact adults' proficiencies (Reder, 2009a, 2009b; Saal et al., 2018). This theory has salient implications for accountability of adult education programs - and for their impact. "Adult education programs are more closely aligned with practice engagement measures than with proficiency measures. Program participation leads to increased practice engagement that, over time, leads to" gains in 
learning (Reder, 2009a, p. 35). Holding programs accountable for valid and reliable growth in engagement in numeracy practices "would be a more effective way to assess program impact" (Reder, 2009b, p. 80). Coben and Alkema (2017) add that when increases in numeracy practices are not reflected in increased gains in learning, learners and instructors can feel frustrated.

\section{Numeracy Skills and Health}

A final factor of importance, though sparsely investigated in PIAAC for adult ELs, is health (Jonas, 2018; Prins \& Monnat, 2015), particularly for middle-aged and older adults (Cummins et al., 2018). Researchers note that middle-aged and older adults face higher risks of health-related problems (Jonas, 2018; Yamashita, Bardo, \& Liu, 2018). Numeracy skills, and even more so numeracy skill use, appear to predict healthrelated outcomes and behaviors than do literacy skills (Jonas, 2018).

Having strong skills in numeracy permits adults to understand health risks, make informed health decisions, and manage health conditions (Cummins et al., 2018; Feinberg, Greenberg, \& Frijters, 2015; Jonas, 2018; Prins \& Monnat, 2015; Yamashita et al., 2018). Prins and Monnat (2015) note, “despite immigrants' low literacy and numeracy scores and disadvantaged socioeconomic position relative to their U.S.-born peers, they generally reported better health" ( $p$. 18). "Better understanding of numeracy skills" in relation to health "will be a logical next step" (Cummins et al., 2018, p. 21).

\section{Research Questions}

This paper's purpose, as stated in the introduction, is to examine numeracy skills and skill use at home of adult ELs. Numerous PIAAC studies have reviewed U.S. numeracy data from 2012; however, few studies analyze the latest U.S. data (i.e., 2012/2014) or PIAAC data on older adults, and none specifically investigates numeracy skills and at-home use of adult ELs. To begin to fill this gap, three research questions have been developed:

1. What are average numeracy skill levels and numeracy at-home use rates of adult English learners (ELs) in the aggregate?

2. Controlling for education attainment, family background, and health, how does numeracy at-home use of adult ELs predict numeracy skill levels?

3. How does numeracy at-home use of adult ELs differ among discrete groups based on covariates (from Research Question [RQ] 2) and numeracy skill levels? What are descriptive characteristics of each group?

\section{Methods}

\section{Sample}

PIAAC:2012 surveyed and assessed 5,010 U.S. adults ages 16 to 65 years. Supplemental data from 2014 extend the U.S. sample to 8,670 adults and include key subgroups: unemployed adults (ages 16 to 65 ), young adults (ages 16 to 34 ), and older adults (ages 66 to 74 ).

PIAAC:2012/2014 data collection employed a complex sampling design to ensure representativeness in the population (Hogan et al., 2016). PIAAC:2012/2014 data files are assembled from public-use files that perturb and categorize individual data to ensure confidentiality. Weights are applied to ensure that respondents in the sample represent an accurate population proportion and that standard errors reflect variability estimated in the population rather than in the sample. Replicate weights facilitate 
calculating unbiased estimates and standard errors. More detail on sampling, weighting, background questionnaire administration, and assessments is available in Hogan et al. (2016).

The full sample from PIAAC:2012/2014 was limited for this paper to 494 U.S. adults ages 25 to 74 years experiencing challenges with English proficiency, and who are first-generation immigrants. English proficiency was determined from a score comprised of a summed measure of four U.S.-specific variables indicating respondents' self-reported ability to speak, read, write, and understand spoken English (J_Q05cUSX3a, 3b, 3c, and $3 \mathrm{~d}$ ), where higher composite scores represent less proficiency (Prins \& Monnat, 2015). Adults with English proficiency scores of 6 through 16 were included (i.e., summed scores in which respondents rated at least one measure "well," "not well," or "not at all"). This final sample of 494 represents approximately 16 million U.S. adults.

\section{Variables for Numeracy Skills and At-Home Use}

Selected adults took surveys and assessments on laptop computers. They completed an extensive background questionnaire and assessments in literacy, numeracy, and problem-solving in technology-rich environments. The background questionnaire (BQ) contains 10 sections of items measuring general information, education background, employment, skill use, personal characteristics, health, and family background. Analyses in this paper rely on multiple BQ items. Adult ELs completed the BQ in English (62.3\%) or in Spanish (37.7\%).

PIAAC "offers a measure of proficiency level, based on a standardised numeracy assessment, and a measure of intensity of adults' use of numeracy, based on self-reported questions about" participants' "use of numeracy-related skills and/ or reasoning" (Jonas, 2018, p. 10). Assessment scores are estimated using 10 plausible values per content domain. Scores range from 0 to 500 and are classified into one of five levels. Numeracy levels are: below Level 1 (0-175), Level 1 (176-225), Level 2 (226-275), Level 3 (276-325), and Levels 4 / 5 (326500), according to Rampey et al. (2016). All 494 ELs completed the numeracy assessment in English.

PIAAC BQ also collects information on how often adults engage in numeracy-related activities at home. Responses range from "never" to "every day". PIAAC respondents are asked about six numeracy activities, two reading activities that "involve accessing numerical and mathematical information and representations that have a mathematical dimension" (Jonas, 2018, p. 13), and two technology activities involving calculations or financial knowledge. The 10 at-home use items with numeracy components are shown in Table 1.

\section{Control and Descriptive Variables}

Three covariates are employed for analyses in Research Question 2 (RQ2). These covariates include educational attainment, parental education, and self-reported health status. Respondents' educational attainment is measured in three categories: less than high school (LHS), high school (HS), and postsecondary (PSE) levels (Krupar et al., 2017). Parent's highest education level is the higher of either mother's or father's education attainment, dummy coded (0) to less than high school (LHS) or high school or college degree (1); 26 adults did not know their parents' education attainment so are missing these data. Self-reported health status is coded to excellent, very good, or good (0), contrasted with fair or poor health (1).

Descriptive variables include age, gender, income, family characteristics, and health-related variables. Respondents' ages are grouped into 10 categories of 5-year age bands: 25-29, 30-34, 35-39, 40-44, 45-49, $50-54,55-59,60-65,66-70$, and 71-74 years. Gender 


\section{Table 1: Items for At-Home Use of Numeracy Skills}

\begin{tabular}{|l|l|}
\hline ITEM & WORDING: IN EVERYDAY LIFE, HOW OFTEN DO YOU USUALLY... \\
\hline H_Q01g & Read bills, invoices, bank statements or other financial statements? \\
\hline H_Q01h & Read diagrams, maps, or schematics? \\
\hline H_Q03b & Calculate prices, costs or budgets? \\
\hline H_Q03C & Use or calculate fractions, decimals or percentages? \\
\hline H_Q03d & Use a calculator - either hand-held or computer based? \\
\hline H_Q03f & Prepare charts, graphs or tables? \\
\hline H_Q03g & Use simple algebra or formulas? \\
\hline H_Q03h & $\begin{array}{l}\text { Use more advanced math or statistics such as calculus, complex algebra, trigonometry, or use of regression } \\
\text { techniques? }\end{array}$ \\
\hline H_Q05d & Conduct transactions on the internet, for example buying or selling products or services, or banking? \\
\hline H_Q05eł & Use spreadsheet software, for example Excel?
\end{tabular}

Notes: Frequency of responses includes never, less than once a month, less than once a week but at least once a month, at least once a week but not every day, every day. *According to PIAAC BQ, as cited in Curry (2017, p. 4), "By simple algebra or formula, we mean a mathematical rule that enables us to find an unknown number or quantity, for example a rule for finding an area when knowing length and width, or for working out how much more time is needed to travel a certain distance if speed is reduced." \# Both technology variables (H_Q05d and e) contained substantial missing data ( $n=224$ and 225 , respectively) because many adults had reported earlier not ever using a computer so were legitimately not asked the question. For RQ2 regression analyses, these variables were recoded, with "not asked" becoming "never", to maximize the sample for regression analyses.

is dichotomized as male and female. Respondents' monthly income is measured by a derived ordinal rank variable (EARNMTHALLDCL) with 10 deciles. Work status (C_Q07) indicates full- and part-time employment, as well as rates for those primarily in the home or on permanent disability. Family characteristics are measured by two dichotomous variables: living with spouse/partner or not and having a child(ren) or not. Additional health-related variables that could relate to numeracy skills and at-home use are having vision difficulties or hearing difficulties (versus not having the difficulty, respectively).

\section{Analyses}

RQ1 analyses were conducted in the aggregate using International Data Base (IDB) Analyzer
4 and SPSS 24, employing measures of central tendency for all 494 adult ELs. Means, standard errors (SE), and standard deviations (SD) are calculated for numeracy skills, with Cohen's $d$ as effect size representing magnitude of mean differences from overall population score means. For five numeracy skill use categories, medians are reported. Sample and replicate weights are applied in all analyses. All analyses in this paper were descriptive, and causality should not be inferred.

Plausible values were calculated for estimates of scores in numeracy in RQ1 and for regression analyses in RQ2. In the first regression model for RQ2, numeracy scores were regressed on educational attainment, parental education, and self-reported health status. A second model 
added in three composites of summed at-home numeracy skill use variables: 1 ) use of basic or advanced math skills (summed H_Q03c, d, g, and h), 2) use of numeracy skills for organization (summed H_Q01h, H_Q03f, and H_Q05e), and 3) use of financial numeracy skills (summed $\mathrm{H}_{-}$ Q01g, H_Q03b, and H_Q05d). Possible composite values ranged from 3 (i.e., "never" on all uses) to 20 (i.e., "daily" on most uses) for basic and advanced math use, 3 to 14 for use of numeracy for organization, and 3 to 15 for use of financial numeracy skills. For RQ2 regression analyses, H_Q05d and H_Q05e were recoded, with "not asked" becoming "never" to maximize the sample for regression analyses.

In addressing RQ3, six discrete groups ( $n$ 401) are identified from PIAAC data, based on EL education, parent education, and health status. Groups are named for education attainment (low, mid, or high) and prominent generation (Millennial, Gen X, or Baby Boomer). Each group is analyzed categorically for its use of specific numeracy skills and descriptively as explained earlier. Skill-use patterns in the three composites are also analyzed categorically for the six groups.

\section{Results}

\section{Research Question 1}

The mean numeracy skill score for adult ELs is 207.8 (SE 4.5, SD 61.7), or an average Level 1 for numeracy skills. As displayed in Figure 1, numeracy percentiles range from a mean score of 83.6 (Below Level 1) in the first percentile to 359.5 (Level 4/5) in the $99^{\text {th }}$ percentile. ELs taking the Spanish BQ have a significantly lower mean score
(172.2, SE 3.2, SD 49.1) than those taking the English BQ (229.3, SE 3.2, SD 58.4) The difference between the numeracy score means of ELs taking the English or the Spanish BQ ( $d$ 1.06) is large, in favor of adult ELs taking the English BQ. For reference, the estimated mean numeracy score for the overall PIAAC 2012/2014 population was 257 (SE 1.1, SD 54.4), or Level 2, in Saal et al. (2018, p. 14). The difference between the score means of ELs (irrespective of BQ language) and the general population $(d-0.85)$ is also large, to the disadvantage of adult ELs.

In the aggregate, adult ELs indicate at-home use of financial numeracy skills most often. As shown in Figure 2, medians for financial statement review, conducting online transactions, and calculating costs or budgets were at least monthly. An estimated $45.3 \%$ of adult ELs review financial statements weekly or daily, $37.7 \%$ conduct online transactions weekly or daily, and $48.9 \%$ calculate costs or budgets weekly or daily. A fourth (or less) of adult ELs report never reading financial statements, conducting transactions online, or calculating costs or budgets.
Figure 1. Percentile distribution of mean numeracy scores of adult ELS

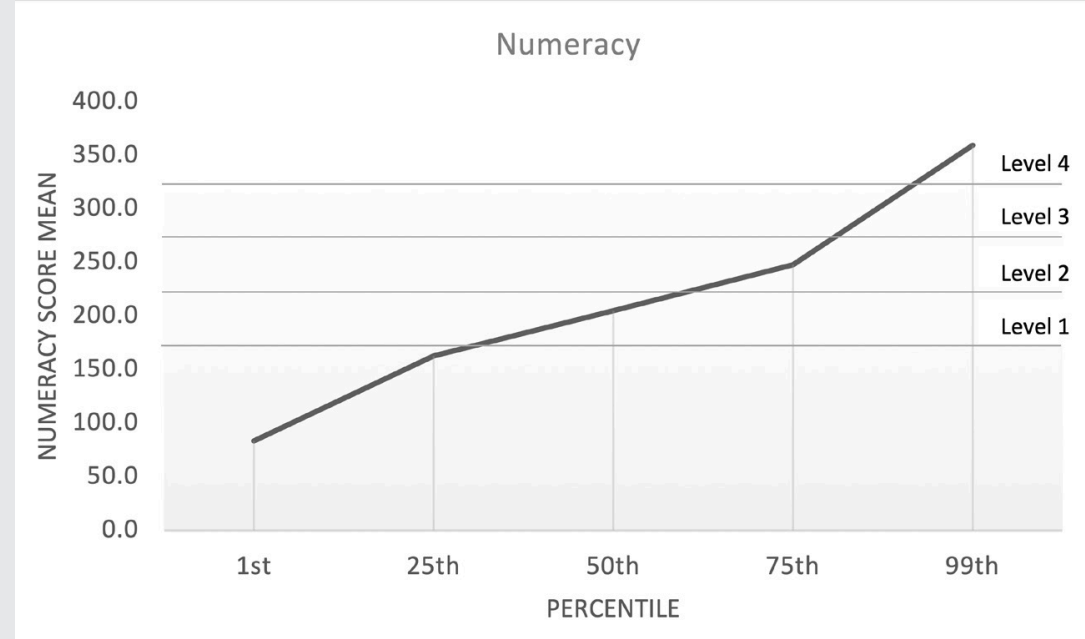

(Source: PIAAC 2012/2014) 
Adult ELs report infrequently using basic math skills at home, and the majority report never using advanced math skills in daily life. Less than monthly was the median for calculating fractions or percentages and for using a calculator; nearly half (48.5\%, SE 2.5) report never calculating fractions or percentages at home, and 35.8\% (SE 2.5) never using a calculator. More than threefourths of adult ELs (77.5\%, SE 2.2) report never

\section{Figure 2. Frequency distribution of financial numeracy skills of adult ELs}

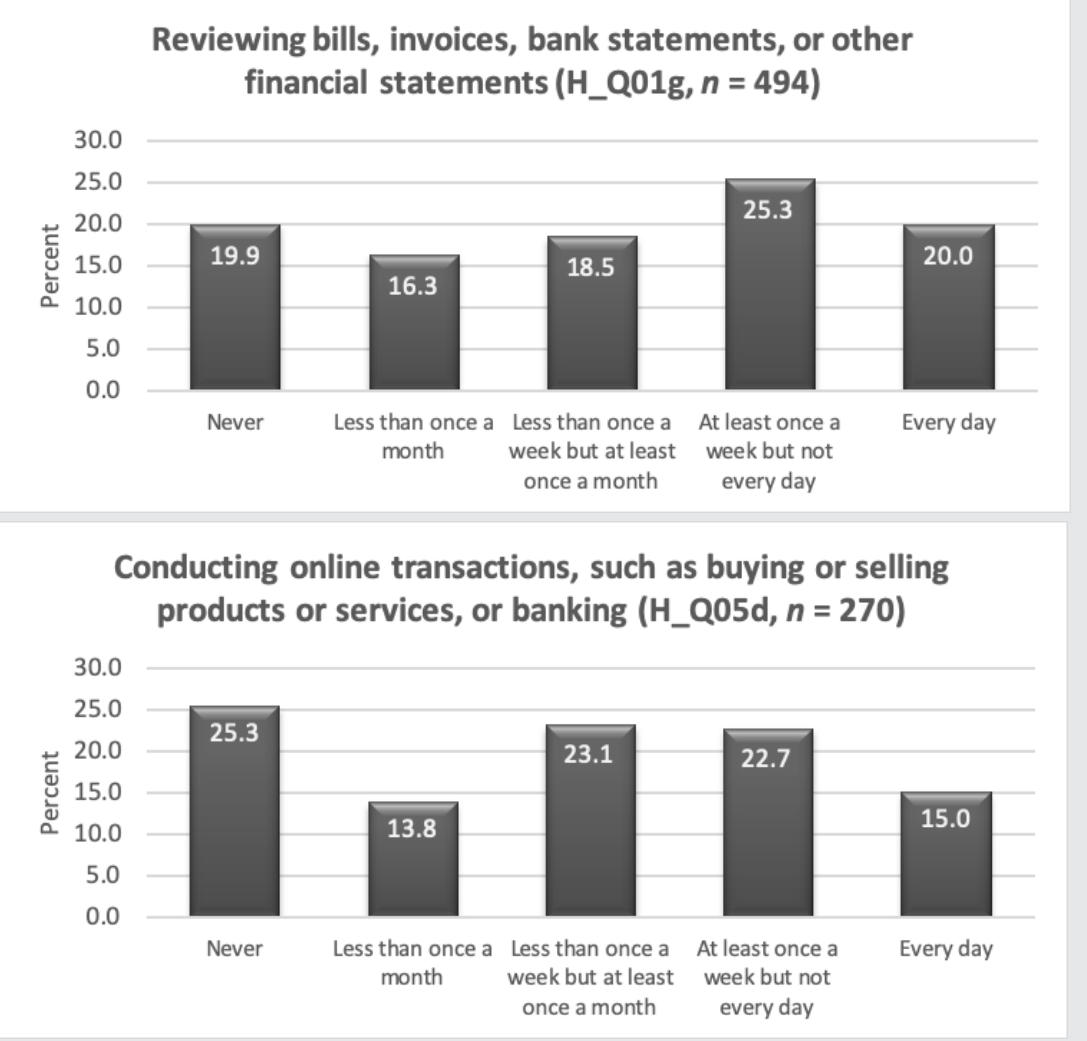

Calculating prices, costs, or budgets (H_Q03b, $n=492$ )

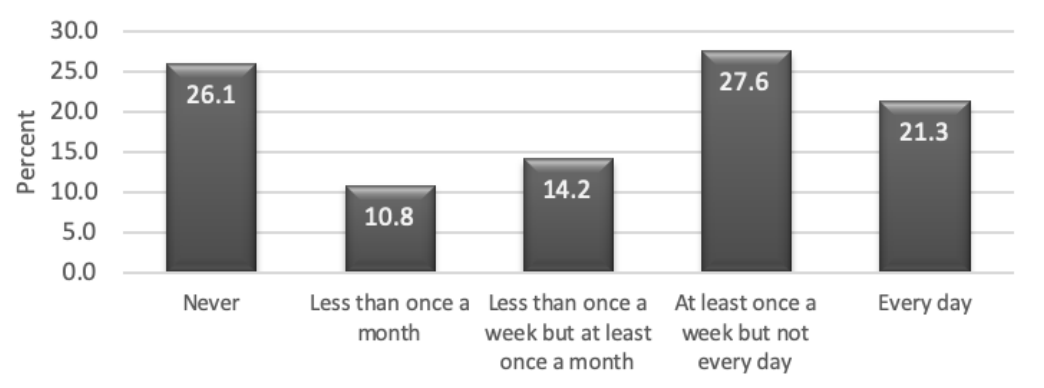

(Source: PIAAC 2012/2014) using simple algebra or formulae, and $90.4 \%$ (SE 1.7) indicate never using advanced math or statistics at home.

In daily life, most adult ELs indicate never employing numeracy skills to organize information. The median was "never" for reading diagrams, maps, and schematics (61.4\%, SE 2.8), for using spreadsheets on a computer $(68.9 \%, S E$ 3.8), and for preparing charts, graphs, or tables $(83.8 \%, S E$ 1.5).

\section{Research Question 2}

Education attainment, family background, and health, as explained in the literature review, are important predictors of numeracy skills, though generally difficult to change. According to the first regression model, which explains $30 \%$ of variance in numeracy scores (Nagelkerke $R^{2} 0.30$ ), an adult EL with LHS education, parents with LHS education, and good health could expect a mean numeracy score of 205 (Level 1). If this same adult had fair or poor health, the score would decrease to 177 , yet still be in Level 1. If the adult and his or her parent had a postsecondary degree and the adult had good health, the mean numeracy score would increase to 265 (Level 2) - with fair or poor health, the score would decrease to 237 but remain in Level 2. 
With three at-home numeracy skill use composites added (i.e., use of basic or advanced math skills, use of numeracy skills for organization, and use of financial numeracy skills), the percentage of variance explained in the second model increased to $40 \%$ (Nagelkerke $R^{2} 0.40$ ). In this model, an adult EL with LHS education, parents with LHS education, good health, and an answer of "never" on the three numeracy skill use composites could expect a mean numeracy score of 182 (Level 1). Figure 3 displays the predicted mean scores for categories of education, parent education, health and skill use.

Considering education, parental education, and health, an EL's mean score would be predicted to increase by one point for every increment of use of basic or advanced math skills, by two points for every increment of use of numeracy skills for organization, and by three points for every increment of use of financial numeracy skills. The final regression equation was:

162 (starting score) +22.5 (EL has PSE education) - 5.6 (EL has HS education) + 24.4 (parent has HS or PSE education) -23.8 (EL has fair or poor health) +1.1 (basic or advanced math skill use) +2.3 (numeracy skill use for organization) +3.2 (financial numeracy skill use)

If this same EL reported "daily" use of all three numeracy skills composites, as shown in Figure 3, his or her predicted mean numeracy score would increase to 264 (Level 2).

As another example, if an adult EL and his or her parent has a high school education, the EL has good health, and the EL reports "daily" use of all three types of at-home numeracy skills, the mean numeracy score would be predicted as 283 (Level 3). Should this same EL report "never" using any of the three types of at-home numeracy skills, the

Figure 3. Predicted PIAAC Numeracy scores by skill use group of adult ELs

(Source: PIAAC 2012/2014)

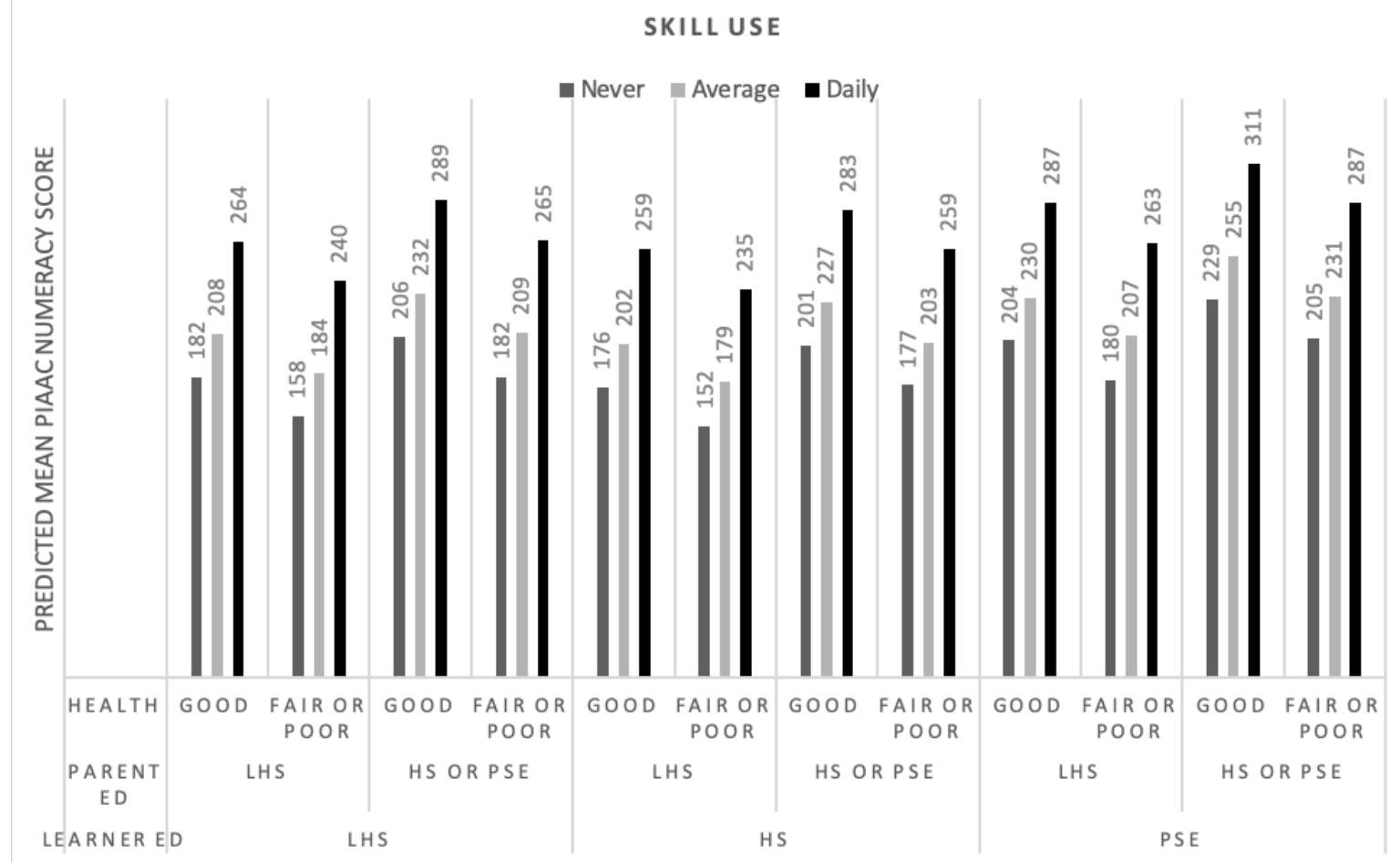

Notes: LHS designates less than high school, HS high school, and PSE postsecondary education. 
predicted mean numeracy score would decrease to 201 (Level 1). Use of numeracy skills therefore can predict substantial variation in PIAAC numeracy scores beyond that predicted by an EL's education attainment, health, and parental education.

\section{Research Question 3}

As shown in Figure 3, numerous groups are identifiable in PIAAC data, based on EL education, parent education, health status, and numeracy skill use pattern. After further review of group size by EL education, parent education, and health status, six discrete groups remain for further analysis. Adult educators may "recognize" adult ELs in these discrete groups through their characteristics; groups were named by education attainment and prominent generation. Characteristics are displayed in Table 2 and median numeracy scores in Figure 4.

The Low Millennial group (1) tends to comprise millenial ELs with low personal and parental education attainment. As displayed in Figure 4, their median PIAAC Numeracy score is 177.6 (SE 10.6). The Low Baby Boomer group (2) tends to be older ELs reporting low personal and parental education attainment and fair or poor health. Twelve percent are on permanent disability, and $34 \%$ report difficulty seeing and 16\% difficulty hearing. Most of the Low Millennial and Low Baby Boomer groups are partnered, and nearly all have children.

Members of the Mid Millennial group (3) report finishing high school, although their parents did not. This group tends to have high levels of fulltime employment yet generally earns an income at approximately $200 \%$ of poverty. The Mid Young Millennial (4) group tends to be the youngest group and is mostly male; these ELs and their parents completed high school, and their parents may have completed PSE. Most of both Mid

Table 2: Characteristics of six groups of adult ELs (Source: PIAAC 2012/2014)

\begin{tabular}{|l|c|c|c|c|c|c|}
\hline GROUP & $\begin{array}{c}\text { LOW } \\
\text { MILLENNIAL }\end{array}$ & $\begin{array}{c}\text { LOW BABY } \\
\text { BOOMER }\end{array}$ & $\begin{array}{c}\text { MID } \\
\text { MILLENNIAL }\end{array}$ & $\begin{array}{c}\text { MID YOUNG } \\
\text { MILLENNIAL }\end{array}$ & $\begin{array}{c}\text { HIGH } \\
\text { GEN X }\end{array}$ & $\begin{array}{c}\text { HIGH YOUNG } \\
\text { GEN X }\end{array}$ \\
\hline Age (Mode in Years) & $35-39$ & $55-59$ & $35-39$ & $25-29$ & $50-54$ & $40-44$ \\
\hline EL Education & LHS & LHS & HS & HS & PSE & PSE \\
\hline Parent Education & LHS & LHS & LHS & HS/PSE & LHS & HS/PSE \\
\hline Health Status & Good & Fair or Poor & Good & Good & Good & Good \\
\hline Female (\%) & 56 & 63 & 59 & 39 & 63 & 60 \\
\hline Income (Decile) & $8^{\text {th }}$ & $8^{\text {th }}$ & $6^{\text {th }}$ & $6^{\text {th }}$ & $5^{\text {th }}$ & $5^{\text {th }}$ \\
\hline Employed FT (\%) & 64 & 57 & 60 & 51 & 50 & 52 \\
\hline Partner (\% Yes) & 82 & 74 & 74 & 84 & 78 & 80 \\
\hline Children (\% Yes) & 91 & 96 & 83 & 82 & 89 & 72 \\
\hline Difficulty Seeing (\%) & 24 & 34 & 11 & 5 & 28 & 9 \\
\hline Difficulty Hearing (\%) & 4 & 16 & 2 & 1 & 5 & 6 \\
\hline Permanent Disability (\%) & 0 & 12 & 0 & 0 & 7 & 0 \\
\hline
\end{tabular}

Notes: *Higher deciles represent lower incomes; $200 \%$ of poverty level is estimated between 5 th and 6 th deciles. LHS designates less than high school, HS high school, and PSE postsecondary education. 


\section{Figure 4. Percentile distribution of mean numeracy scores of adult ELs in 6 groups}

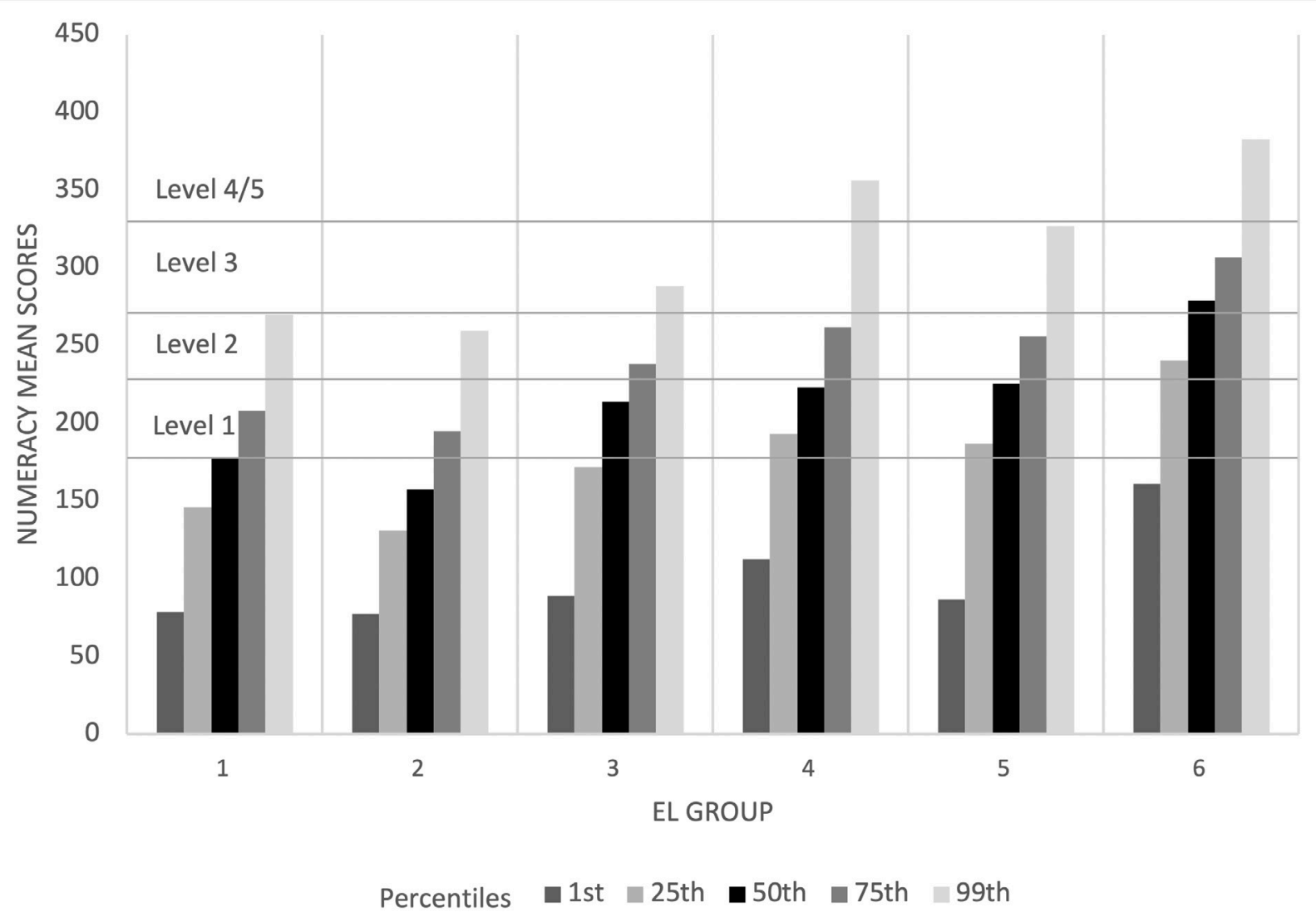

(Source: PIAAC 2012/2014)

Millennial groups are partnered, have children, and report positive health.

High Gen X (5) and High Young Gen X (6) groups completed PSE, but their parents' education varied. Most are women, and about half work full time, with incomes just above $200 \%$ of poverty. Most of High Gen X and High Young Gen X report positive health and are partnered with children. Adult educators can also benefit from knowing specific numeracy skill use of adult ELs in discrete groups - both to understand the potential strengths in numeracy skills they already have and to identify numeracy skills in which they could receive instruction. As displayed in Figure 5 , patterns of at-home numeracy skill use differ by group. Low Millennials and Low Baby Boomers report a median "never" using basic or advanced math skills, and Mid Millennials, Mid Young Millennials, and High Gen X use them less than monthly, on average. Only the High Young Gen $\mathrm{X}$ group indicates a median monthly use of basic and advanced math skills at home.

Low Millennials and Low Baby Boomers report using financial numeracy skills less than monthly, on average. Mid Millennials, Mid Young Millennials, and High Gen X indicate using financial numeracy skills a median of monthly, and the High Young Gen $\mathrm{X}$ group doing so weekly. On using numeracy skills for organization, all groups except the High Young Gen X group report a median "never" using numeracy skills for 

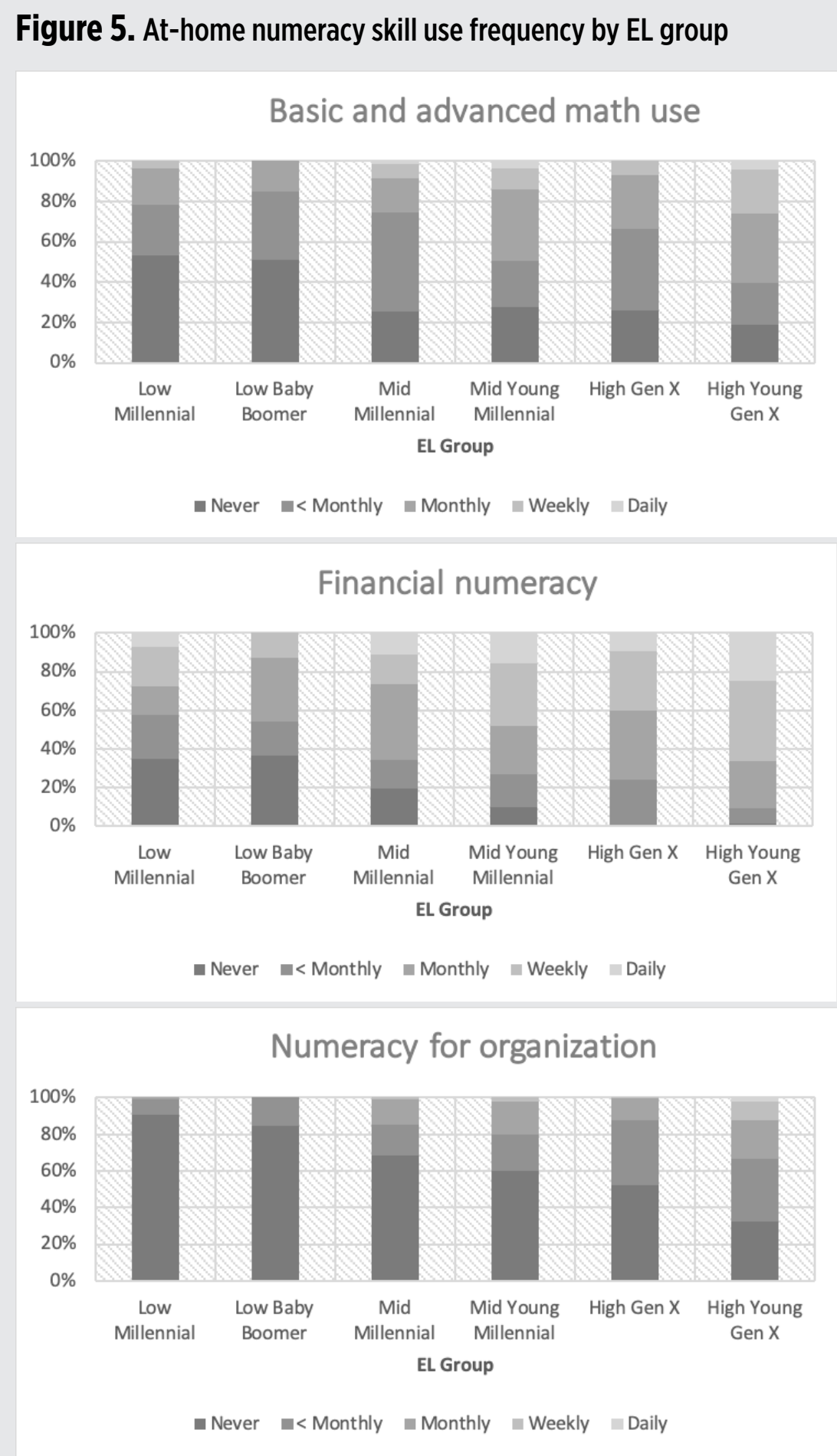

(Source: PIAAC 2012/2014)

\section{Discussion}

\section{Summary of Findings}

Findings are briefly summarized to allow the reader to review overall results before a discussion of implications. Aggregate EL findings include a mean numeracy score of nearly 208 (Level 1), much lower than 257 (Level 2) in the overall population (Saal et al., 2018). Adult ELs tend to use financial numeracy skills most often, including reviewing financial statements, conducting online transactions, and calculating costs or budgets. The majority report using basic math less than monthly and never using advanced math or numeracy to organize information. Use of three types of numeracy skills at home, on top of factors of EL education, health, and parental education, account for $40 \%$ of the variance in numeracy skills, with use of financial numeracy skills the strongest predictor of the three types.

Six discrete groups of adult ELs are identified and described, with groups varying widely in education background, age, income, and health-related characteristics. All six groups could potentially be among the adult education target organization. Only the High Young Gen X group

uses them a median of less than monthly (see

Figure 5). population. Group median scores in numeracy skills range from 157 (below Level 1) to 279 (Level 3). Most members of Low Millennial, Low Baby 
Boomer, and Mid Millennial groups score at Level 1 or below in numeracy, and most of High Gen X and High Young Gen X score at Level 2 or below. Numeracy score levels of adults at levels 5 and 6 are similar to those found in Batalova \& Fix (2015). These scores indicate ample opportunity for numeracy instruction in adult education. All groups, and particularly Low Millennial and Low Baby Boomer groups, could benefit from instruction in use of basic and advanced math and use of numeracy for organizing information. Low Millennial and Low Baby Boomer especially could find instruction in financial numeracy skills beneficial.

\section{Implications for Practice Engagement and Health}

According to this paper's findings, the U.S. general population discrepancy between high use of numeracy skills and relatively low numeracy skills (Grotlüschen et al., 2016; Jonas, 2018) was not replicated for adult ELs; except for financial numeracy, adult ELs seldom use numeracy skills at home. Instead, practice engagement theory (Reder, 2009a, 2009b; Saal et al., 2018) is supported in the relationship of low numeracy use with low numeracy skill levels in the first five groups, and high use with high skill levels in the High Young Gen X group only.

This paper also contributes to the sparsely investigated relationship of adult EL numeracy skills with health (Grotlüschen et al., 2016; Jonas, 2018; Prins \& Monnat, 2015; Cummins et al., 2018). The Low Baby Boomer group, which had high proportions of middle-aged and older ELs, reports high rates of health-related problems - fair or poor health and vision and hearing difficulties (Jonas, 2018; Yamashita, Bardo, \& Liu, 2018). This group also has low rates of numeracy skill use at home and the lowest median scores in numeracy of all groups. The High Gen X group, which also has high proportions of adults in their 50's, has median scores similar to Mid Millennial and Mid Young Millennial groups, and similar rates in vision difficulties as Low Baby Boomers. While these relationships are not causal, they do indicate that adult educators working with adult ELs should be on the watch for health issues, including vision and hearing, that can impact learning and numeracy skill attainment and use.

\section{Implications for Instruction}

The summary of findings indicates that expanding numeracy skill use in basic and advanced math, numeracy for organizing information, and financial numeracy has the potential to benefit numeracy skills of adult ELs. Why is this instruction to enhance numeracy skill use important? One response is it strengthens immigrants ELs' full participation in society (Batalova \& Fix, 2015; Perry, 2017). More personally, it can improve daily life. Curry (2017) answers, "From the minute we wake up we make multiple decisions each day based on numeracy skills" (p. 1). She continues, "Considering the importance of numeracy in our daily lives, it would seem that adults should be fairly proficient at numeracy-related tasks. However, [according to PIAAC findings] that does not appear to be the case."

To support instructional approaches to strengthening numeracy skills, Curry (2017) recommends the PIAAC Numeracy framework (PIAAC Numeracy Expert Group, 2009), which offers guiding "concepts to develop approaches to teaching numeracy" (p. 2). Employing these approaches will ensure "students have the skills they need to use numeracy to carry out important tasks in their daily lives" (Curry, 2017, p. 3). While not specific to ELs, Curry's guide offers adult education instructors approaches to help them think through numeracy instruction and 
adapt it to EL needs. While adapting approaches, EL instructors need to recall challenges of mathematics vocabulary, context, and symbols (Ni Riordain et al., 2015) with potential to confuse adult ELs and think through assumptions about what they recognize, understand, and can do (Sellers \& Byrne, 2015; Stacey, 2016).

Curry (2017) recommends asking questions about adult numeracy skills use (see Table 1), "to determine the types of numerate behaviors they already engage in" (p. 4). Instructors might also begin discussions on how adult ELs employ numeracy skills, perhaps during program orientation or in introducing numeracy lessons within English instruction. Curry (2017) suggests "students could interview each other about where they use math in their lives or how they addressed a situation where math was needed" (p. 4).

Numerate behavior is behavior that "involves managing a situation or solving a problem in a real context, by responding to mathematical content/ information/ideas represented in multiple ways" (Curry, 2017, pp. 5-6). The situation and the context matter in numerate behavior (Ginsburg, 2017), and at-home numeracy skills are focused on meaning (Saal et al., 2018). Curry emphasizes managing the situation or solving the problem. To do so, adults need to use math and apply current knowledge of math concepts and skills. Curry (2017) examines contexts, responses, content, and representations of mathematical ideas - and instructional implications (pp. 7-10). She offers instructional planning examples (pp. 11-23), including resolving a childcare issue through budgeting (intermediatelevel instruction), cost comparisons (low-level instruction), or algebraic reasoning (advanced-level instruction). She adds contextual and complexity factors via examples on calculating costs for a community fair, travel times, dietary needs, and sale discounts (pp. 25-28).

\section{Curry concludes (2017):}

Adopting PIAAC's use-oriented approach to teaching numeracy ... more effectively prepares adults for real life numeracy tasks.... Practitioners who embrace the idea that adults need to become numerate rather than 'learn math' should be able to create tasks that require all aspects of numerate behavior - context, content, responses, and representations... so that all students can continue to become more numerate adults. (p. 29)

\section{Limitations}

Several limitations are noted. First is the PIAAC measurement approach taken for non-English speakers. The BQ relied on self-reported data, whose reliability could vary depending on how well the respondent understood or chose to answer the questions. Also, the BQ was offered in English or Spanish, but skill assessments were offered only in English. Therefore, Spanish-speaking, first-generation immigrants in the dataset selected for this paper were at a disadvantage by taking numeracy assessments in English, and native speakers of all other languages in taking skill assessments and reporting use of skills at home in English.

\section{Conclusions and Recommendations for Future Research}

This paper has contributed new information on U.S. skill levels and skill use in adult EL numeracy. Disaggregating data by BQ language or measures of English proficiency was outside the scope but could generate informative comparisons in future studies. Future researchers could also consider disaggregating data on skill levels and use by length of residence in the United States. Other potentially useful comparisons would be to compare skill levels and use with those of adults from other OECD countries, particularly countries from which sizable proportions of ELs emigrated. In keeping with this issue's theme of broadening 
the lens on adult education, adult educators may wish to consider issues of program design and assessment to support EL numeracy instruction. Program administrators and instructional staff need to consider how EL services are structured so that numeracy skill use and skill levels can increase along with language learning. Can numeracy instruction be added to existing EL classes or tutoring - and if so, how readily could numeracy be incorporated within the context of language instruction? Alternatively, would distinct numeracy classes or tutoring need to be offered? Adult educators could consider seeking grants from funders interested in strengthening health literacy or financial literacy in adults, to supplement instruction or contextualize numeracy.

Also, given disparity in numeracy skills of ELs taking English vs. Spanish BQs, asking how ELs can be assessed for numeracy skills fairly, in the language they use most often, is reasonable. Future research could investigate available numeracy skill assessments in Spanish and other frequently spoken languages with validity evidence for adults, and researchers could make recommendations for assessment use in programs. While assessments might, or might not, meet National Reporting System requirements, they could provide diagnostic guidance, demonstrate learner progress in numeracy, and inform instruction without penalizing ELs for language skill differences. 


\section{References}

Batalova, J., \& Fix, M. (2015). What does PIAAC tell us about the skills and competencies of immigrant adults in the United States? Retrieved from https://static1. squarespace.com/static/51bb74b8e4b0139570ddf020/t/ 54da7824e4b026d7c8ca7cce/1423603748680/ Batalova_Fix_PIAAC.pdf

Batalova, J. and Fix, M. (2016). Literacy and numeracy skills of second-generation young adults: A comparative study of Canada, France, Germany, the United Kingdom, and the United States. Retrieved from https://static1.squarespace.com/ static/51bb74b8e4b0139570ddf020/t/578d1e95579fb36 0acc952bf/1468866198724/Batalova_Fix_PIAAC.pdf

Coben, D., \& Alkema, A. (2017). The case for measuring adults' numeracy practices. Journal of Research and Practice for Adult Literacy, Secondary, and Basic Education, 6(1), 20-32.

Cummins, P. A., Yamashita, T., and Arbogast, A. (2018). An examination of PIAAC Data for unemployed adults aged 45-74. Retrieved from https://piaac.squarespace. com/s/Cummins-Yamashita-Arbogast_2018.pdf

Curry, D. (2017). Using the PIAAC Numeracy Framework to guide instruction: An introduction for adult educators. Retrieved from https://static1.squarespace. com/static/51bb74b8e4b0139570ddf020/t/58891aa81b 631b5929d4c05f/1485380267014/Numeracy_Guide_ Curry_2017.pdf

Feinberg, I., Greenberg, D., \& Frijters, J. (2015). Understanding health information seeking behaviors of adults with low literacy, numeracy, and problem solving skills: Results from the 2012 U.S. PIAAC study. Retrieved from https://static1.squarespace.com/ static/51bb74b8e4b0139570ddf020/t/54da7889e4b00 4762df45b52/1423603849970/Feinberg_Greenberg_ Frijters_PIAAC.pdf

Ginsburg, L. (2017). What's an adult numeracy teacher to teach?: Negotiating the complexity of adult numeracy instruction. Journal of Research and Practice for Adult Literacy, Secondary, and Basic Education, 6(1), 57-61.
Green, A., Green, F., \& Pensiero, N. (2015). Cross-country variation in adult skills inequality: Why are skill levels and opportunities so unequal in anglophone countries? Comparative Education Review, 59(4), 595-618. doi:10.1086/683101

Grotlüschen, A., Mallows, D., Reder, S., \& Sabatini, J. (2016). Adults with Low Proficiency in Literacy or Numeracy. OECD Education Working Papers, No. 131. Paris, France: OECD Publishing. doi:10.1787/5jm0v44bnmnx-en

Hogan, J., Thornton, N., Diaz-Hoffmann, L., Mohadjer, L., Krenzke, T., Li, J., \& VanDeKerckhove, W. (2016). Program for the International Assessment of Adult Competencies (PIAAC) 2012 and 2014: U.S. Main Study and National Supplement Technical Report (NCES 2016-036). U.S. Department of Education. Washington, DC: National Center for Education Statistics. Retrieved from http://nces.ed.gov/pubsearch

Jonas, N. (2018). Numeracy practices and numeracy skills among adults, OECD Education Working Papers, No. 177. Paris, France: OECD Publishing. doi: $10.1787 / 8 f 19 f c 9 f-e n$

Krupar, A., Horvatek, R., \& Byun, S. (2017).

Does nonformal education matter? Nonformal education, immigration, and skills in Canada. Adult Education Quarterly, 67(3),186-208. doi:10.1177/0741713617697423

Lind, P., \& Mellander, E. (2016). Relations between immigration and adult skills: findings based on PIAAC. Working Paper No. 21. Uppsala: Institute for Evaluation of Labour Market and Education Policy. Retrieved from https://www.econstor.eu/ bitstream/10419/166022/1/880232609.pdf

Massing, N., \& Schneider, S. L. (2017). Degrees of competency: The relationship between educational qualifications and adult skills across countries. Largescale Assessments in Education, 5(6). doi:10.1186/ s40536-017-0041-y 
Ní Ríordáin, M., Coben, D., \& Miller-Reilly, B. (2015). What do we know about mathematics teaching and learning of multilingual adults and why does it matter? Adults Learning Mathematics: An International Journal, 10(1), 8-23. Retrieved from https://files.eric. ed.gov/fulltext/EJ1077722.pdf

OECD. (2009). PIAAC BQ JRA V5.0 - Conceptual framework. Paris, France: OECD Publishing.

OECD. (2013). Technical report of the Survey of Adult Skills (PIAAC): Prepublication Copy. Paris, France: OECD Publishing.

OECD. (2018). Skills on the move: Migrants in the Survey of Adult Skills. OECD Skills Studies. Paris, France: OECD Publishing. doi:10.1787/9789264307353-en

Paccagnella, M. (2016). Age, ageing and skills: Results from the Survey of Adult Skills. OECD Education Working Papers, No. 132. Paris, France: OECD Publishing. doi: 10.1787/5jm0q1n381vc-en

Perry, A. (2017). Are over-qualified immigrants mismatched according to their actual skills? An international comparison of labor market placement in OECD countries. GESIS Papers No. 2017|19. Cologne: GESIS - Leibniz-Institute for the Social Sciences. Retrieved from http://www.ssoar.info/ssoar/handle/ document $/ 52592$

PIAAC Numeracy Expert Group. (2009). PIAAC Numeracy: A conceptual framework. Paris, France: OECD Publishing. Retrieved from http:/www.oecd.org/edu/ oecdprogrammefortheinternationalassessmentofadult competenciespiaac-documentation.htm

Prins, E., \& Monnat, S. (2015). Examining associations between self-rated health and proficiency in literacy and numeracy among immigrants and US-born adults: Evidence from the Program for the International Assessment of Adult Competencies (PIAAC). Plos One, 10(7), 25. doi:10.1371/journal.pone.0130257
Rampey, B. D., Finnegan, R., Goodman, M., Mohadjer, L., Krenzke, T., Hogan, J., \& Provasnik, S. (2016). Skills of U.S. unemployed, young, and older adults in sharper focus: Results from the Program for the International Assessment of Adult Competencies (PIAAC) 2012/2014: First look (NCES 2016-039rev). U.S. Department of Education. Washington, DC: National Center for Education Statistics. Retrieved from: http://nces.ed.gov/ pubsearch

Reder, S. (2009a). Scaling up and moving in: Connecting social practices views to policies and programs in adult education. Literacy \& Numeracy Studies, 16(2), 35-50. Retrieved from https://www.learning-analytics.info/ journals/index.php/lnj/article/view/1276

Reder, S. (2009b), The development of literacy and numeracy in adult life. In S. Reder and J. Bynner (Eds.), Tracking adult literacy and numeracy: Findings from longitudinal research (pp. 59-84). New York and London: Routledge.

Reder, S. (2013). Lifelong and life-wide adult literacy development. Perspectives on Language and Literacy, $39(2), 18-21$.

Saal, L.K., Gholson, M., Machtmes, K., \& Machtmes, R. (2018). Associations between adults' numeracy skills and employment status: An analysis of PIAAC's U.S. dataset. Retrieved from https://static1.squarespace. com/static/51bb74b8e4b0139570ddf020/t/5be4 86bcf950b74caa092c42/1541703356167/2018 Saal_Gholson_Machtmes_Machtmes_Numeracy_ EmploymentStatus.pdf

Scandurra, R., \& Calero, J. (2017). Modelling adult skills in OECD countries. British Educational Research Journal, 43(4), 781-804. doi:10.1002/berj.3290

Sellers, D, \& Byrne, T. (2015). Numeracy into action: Putting numeracy research into practice. Irish Journal of Adult and Community Education, 112-120. Retrieved from https://files.eric.ed.gov/fulltext/EJ1077740.pdf 
Smith, M. C. (2009). Literacy in adulthood. In M. C. Smith (Ed.), Handbook of Research on Learning (pp. 601635). New York, NY: Routledge.

Stacey, J. (2016). Does adding mathematics to English Language learners' timetables improve their acquisition of English? Adults Learning Mathematics: An International Journal, 11(2), 52-57. Retrieved from https://files.eric.ed.gov/fulltext/EJ1123373.pdf

Storen, L. A., Lundetrae, K, \& Boring, P. (2018). Country differences in numeracy skills: How do they vary by job characteristics and education levels? International Journal of Lifelong Education, 37(5), 578-597. doi:10. 1080/02601370.2018.1554718
Yamashita, T., Bardo, A. R., \& Liu, D. (2018). Numeracy skills, health information-seeking, and preventative health behaviors among middle and older aged adults in the U.S. Retrieved from https://static1.squarespace. com/static/51bb74b8e4b0139570ddf020/t/5b50a5b80 e2e72f3e4d63ae5/1532011961211/Yamashita_Bardo_ Liu_Health_Report2018_Final.pdf

Yamashita, T., \& Kunkel, S. R. (2015). An international comparison of the association among literacy, education, and health across the United States, Canada, Switzerland, Italy, Norway, and Bermuda: Implications for health disparities. Journal of Health Communication, 20(4), 406-415. doi:10.1080/10810730.2014.977469 